\title{
Behavioral treatments for children and adults who stutter: a review
}

This article was published in the following Dove Press journal:

Psychology Research and Behavior Management

8 June 2013

Number of times this article has been viewed

\author{
Michael Blomgren \\ Department of Communication \\ Sciences and Disorders, University \\ of Utah, Salt Lake City, UT, USA
}

Correspondence: Michael Blomgren Department of Communication Sciences and Disorders, University of Utah, 390 S. I 530 E., Rm I2 I0, Salt Lake City, UT 84I I2-0252, USA Email michael.blomgren@health.utah.edu

\begin{abstract}
This paper provides a brief overview of stuttering followed by a synopsis of current approaches to treat stuttering in children and adults. Treatment is discussed in terms of multifactorial, operant, speech restructuring, and anxiolytic approaches. Multifactorial and operant treatments are designed for young children who stutter. Both of these approaches involve parent training and differ primarily in their focus on reducing demands on the child (multifactorial) or in their use of response contingent stimulation (operant conditioning). Speech restructuring and anxiolytic approaches are used with adults who stutter. Speech restructuring approaches focus on the mechanics of speech production, and anxiolytic treatments tend to focus on the symptoms and social and vocational challenges of stuttering. The evidence base for these different approaches is outlined. Response contingent therapy (for children) and speech restructuring therapy (for adults) have the most robust empirical evidence base. Multifactorial treatments for children and stuttering management approaches for adults are popular but are based on theoretical models of stuttering; the evidence base is not robust and tends to be inferred from work in areas such as cognitive behavior therapy and desensitization. Comprehensive, or holistic, approaches to treating stuttering are also discussed. Comprehensive approaches for treating stuttering in adults address both improved speech fluency and stuttering management.
\end{abstract}

Keywords: stuttering, treatment, stuttering management, speech restructuring, cognitive restructuring

\section{Introduction}

Stuttering is a developmental speech disorder in which the forward flow of speech is interrupted by repetitions of sounds, words, and/or the prolongation of sounds. Developmental stuttering appears during the preschool years, typically between the ages of 2 and 4. Stuttering can be quite variable, especially in childhood. It is not uncommon for stuttering to appear and disappear in cycles during the preschool years. Stuttering in children and adults may also vary depending on the speaking context. Stuttering is also more pronounced when an individual is rushed or in a stressful speaking situation. In fact, one of the few invariant aspects of stuttering is that it is highly variable.

The reported incidence numbers for stuttering vary, but stuttering is most common in young children (approximately 5\%). Approximately $0.5 \%$ to $1 \%$ of adults stutter. ${ }^{1}$ These numbers indicate that most children (about 75\%) recover from stuttering naturally, although obviously not all do. Currently, no foolproof indicators exist to determine if an individual child will naturally stop stuttering or not; however, gender and family history of natural recovery appear to be predictors of natural recovery. Girls are more likely to stop stuttering than boys and children with a family history 
of natural recovery from stuttering are more likely to stop stuttering. ${ }^{2}$

On the surface, stuttering is a disorder of speech production. It is not a language disorder or a communication disorder secondary to other emotional or mental conditions. Specifically, surface elements of stuttering include the speech motor behaviors of repeated articulatory movements (eg, t-t-t-talk) and/or fixed articulatory postures (eg, mmmine). ${ }^{3}$ These two broad categories account for the majority of stuttering moments. These stuttering moments may also be accompanied by muscle tension and signs of struggle to speak. Other nonverbal gestures include behaviors such as facial grimaces, eye blinking, and loss of eye contact. These nonverbal gestures are reactive responses at the moment of stuttering and are not considered "core" stuttering behavior. Verbal interjections (eg, "uh," "like," “um," etc) and circumlocutions are also common secondary behaviors.

The surface features of stuttering are those most readily visible to an observer. However, stuttering is more than its surface manifestations. Stuttering is also a multidimensional disorder. 4,5 Aspects of stuttering that exist "below the surface" include private and affective aspects of stuttering. ${ }^{6}$ It should be obvious that people who stutter do not enjoy stuttering. Therefore, stuttering speakers often develop numerous avoidance strategies. These strategies include avoiding problematic words, avoiding stressful speaking situations, or avoiding talking with people where a history of excessive stuttering exists. Examples of particularly stressful speaking situations include talking on the telephone, introducing themselves or others, or talking with authority figures. For many who stutter, avoidance behaviors can be the most handicapping aspect of the disorder. Avoidance behaviors may lead to reduced social and occupational participation. Over time, avoidance behaviors may also lead to negative affective functioning such as feelings of loss of control, decreased mood, and increased anxiety. ${ }^{7}$

Stuttering impacts many facets of daily life. Most people project their identities, their knowledge, and their thoughts and beliefs through verbal communication. When verbal communication is a challenge, the ability to present oneself as a "whole" person also becomes difficult. Many people who stutter feel frustration, anger, embarrassment, self-doubt, and sometimes even shame related to their stuttering. School age children in particular may feel anger and embarrassment when called upon in class to read aloud or provide answers to questions. Adults who rely on clear and effective communication in their jobs often find their stuttering becomes an impediment to attaining their vocational potential. ${ }^{8}$
In addition to the observable communication challenges, for some, stuttering may also lead to social anxiety or social phobia. ${ }^{7}$ Social phobia involves an extreme and debilitating fear of humiliation, embarrassment, and negative evaluation by others. Stuttering, combined with the effects of social phobia, may lead to problems in maximizing one's potential in social, interpersonal, and professional relationships.

The exact cause of stuttering is unknown; however, it is widely accepted that stuttering is primarily due to a problem with the neural functioning that underlies speech production. In that respect, stuttering is a physical disorder and is not considered a mental disorder per se. Stuttering is not caused by nervousness, stress, or parenting styles. ${ }^{9}$ Numerous neuroimaging studies have reported different brain activation patterns between stuttering and non-stuttering speakers. ${ }^{10,11}$ Many of these differences are identified during silent, or inner, speech tasks indicating that differences may exist in the linguistic or motor planning stages of speech production. There may also be timing issues in speech and language areas of the brain that result in stuttering. ${ }^{12}$ About $60 \%-70 \%$ of stuttering speakers also have relatives who stutter, indicating that there is a heritability link. However, the exact form of genetic transmission is unclear. While stuttering is primarily a neurophysiological problem, complex interactions between speech motor, cognitive, social, and emotional needs likely mediate the disorder.

Speech-language pathologists (SLPs) are the appropriate providers of stuttering treatment. SLPs (also known as speech therapists) receive extensive training in the identification and remediation of communication disorders, including stuttering. Many countries require SLPs be licensed and/or certified by national accrediting bodies. Stuttering assessment includes interviewing patients to assess their levels of speech difficulty and ascertain their levels of concern. The SLP then administers a series of formal and informal tests to determine the severity of the disorder. Treatment begins with identifying treatment options for the client and working collaboratively to develop the best individualized treatment plan.

There are currently two basic approaches to treatment for both children and adults who stutter. The methods for children and adults are understandably different, but for both age groups there exists a historical dichotomy in approaches. For children, the dichotomy involves indirect versus direct treatment; that is whether the emphasis of treatment is manipulating environmental factors (indirect) or whether the emphasis is working exclusively on the speech of the child (direct). For adults, the differences exist primarily in the relative emphasis placed on changing either core speech 
behavior or treating knowledge, acceptance, stress, and anxiolytic issues secondary to the core stuttering disorder.

The purpose of the remainder of this article is to provide examples of modern treatments for stuttering in children and adults. There are numerous specific treatments for stuttering, and it would be impossible to review them all in a review article such as this. Interested readers are encouraged to consult a variety of excellent textbooks for in-depth reviews of treatment approaches. ${ }^{1,13-17}$ In this paper, a small number of exemplary treatment approaches will be described. Within each of the age groups, two broad treatment categories will be discussed: those that focus primarily on the core speech disorder and those that focus on the symptomatic or environmental aspects of the disorder. Examples of speech-centric approaches include the Lidcombe Treatment Approach for children and speech restructuring treatments for adults. Examples of symptomatic approaches include multifactorial treatments for children and stuttering management for adults.

\section{Treatments for children}

Treatments for children who stutter have historically been less structured than many approaches for adults. One reason may be that, for many decades, there was a "hands off the child" attitude toward stuttering treatment and children. ${ }^{14}$ This situation was prevalent in the United States from the 1940s through the 1970s. The belief was that directly addressing stuttering in a child could make the situation worse. To some extent this belief is still held by many SLPs. However, studies motivated by operant conditioning indicated the opposite to be true: stuttering can be reduced by calling attention to it. ${ }^{18}$

During the past 20-30 years, the focus from indirect treatments (working solely with the caregivers) has yielded to more direct treatments (having the child be the focus of the intervention). Parental involvement does, however, continue to be an essential component of nearly all treatments for young children.

\section{Multifactorial treatment}

Multifactorial treatments for stuttering are based on the notion that multiple factors may trigger and maintain stuttering in preschool children., ${ }^{919}$ The classic example of a multifactorial approach to treating stuttering in preschool children is the Demands and Capacities model. ${ }^{20-22}$ This model posits that stuttering occurs when the speaking demands placed on a child outweigh the child's current capacity for fluent speech. Specifically, stuttering will occur when demands for fluency exceed the child's cognitive, linguistic, motor, or emotional abilities for fluent speech. The speaking demands may be internal, such as those arising from rapidly developing language (typically between the ages of 2 and 5), or through constitutional characteristics of the child, such as perfectionism, high sensitivity, or other speech and language difficulties. External demands may include stress in the family, unrealistically high demands placed on the child by parents, fast talking parents, etc.

Numerous multifactorial-treatment programs exist for preschool or young school-aged children. Examples include the Family Focused Treatment Program ${ }^{23}$ offered at the Stuttering Center of West Pennsylvania (USA), Parent Child Interaction (PCI) therapy, ${ }^{24-26}$ which originated at the Michael Palin Centre in London England, and the ParentChild Groups Program ${ }^{27-29}$ at Vanderbilt University. These approaches are primarily parent- or family-based treatments and are based on the Demands and Capacities Model. The above mentioned treatment programs are founded on the view that the demands for fluency may be modified, and when the demands decrease more fluent speech should follow.

While many examples of multifactorial treatments exist, the Yaruss' Family Focused Therapy approach is outlined below due to its relatively straightforward programmatic structure. The primary goals of the Family Focused Therapy approach are "(a) to help parents learn about stuttering [...] and (b) to help parents implement communication modifications in their interactions with their child that may facilitate the child's development of fluent speech, healthy communication attitudes, and effective communication skills". ${ }^{23}$ The parents are always present during therapy. In fact, the emphasis is on training the parents rather than the child. The parent-child training sessions usually consist of six to eight 45-minute appointment times, with meetings typically scheduled once per week.

The parent-child training is divided into three sections: (a) education and counseling, (b) communication modification training, and (c) review and reassessment. Education and counseling prepare the parents to participate in their child's treatment. Parents learn about the basics of effective communication and the basics of stuttering. Counseling helps parents reduce their anxiety and concerns about their child's stuttering, and teaches parents to respond to their child's stuttering in a supportive and understanding manner. As part of this first component, parents complete a stressor inventory that helps identify potential personality characteristics of the child that may affect the child's communication and speech fluency, as well as environmental factors that may affect 
the child's communication and speech fluency. The parents complete a home charting exercise. Parents observe at least five situations in which their child engages in conversation. They make note of with whom the child is talking, how much stuttering is present, what type of stuttering is present, how aware the child seems about their stuttering, and what the reactions are of the listener. These observations are then discussed at a subsequent appointment.

The second phase of the treatment, communication modification training, involves teaching parents to use strategies intended to facilitate fluent speech production in their child. The strategies include minimizing time pressure, use of "easy, relaxed speech," reducing communication demands by modifying parents' questioning style, reflecting/ rephrasing the child's speech to provide an accurate model, and providing a reassuring communicative environment.

In the final review and reassessment sessions, the SLP may meet with other family members or caregivers such as babysitters and preschool teachers. Warning signs that stuttering may be returning are presented.

Evidence of efficacy for multifactorial approaches is limited, but preliminary studies show stuttering reduction, improved parent awareness of their child's stuttering, and improved capacity to address the stuttering openly. ${ }^{23,24,30}$ Multifactorial treatments have many positive aspects. The positive attributes include the high degree of individualization for each child, the fact that this type of treatment can be started with very young children, and that parents discover that there are factors within their control and factors outside their control. Factors within a parent's control include responding appropriately to stuttering, decreasing rate of speech, and fostering a supportive communicative environment. Factors outside a parent's control include factors like genetic predisposition and temperament. ${ }^{19}$

\section{Operant conditioning and the Lidcombe Program}

The Lidcombe Program was designed for children aged five and younger. It is a parent implemented behavioral treatment developed by clinicians and researchers at the University of Sydney, Australia. The program is named after the Sydney suburb of Lidcombe where the program originated. The primary component of the Lidcombe Program involves teaching parents to use verbal contingencies for unambiguous stuttering during conversations. A secondary component is the measurement of stuttering by both parents and the SLPs.

The Lidcombe Program is based on studies in the 1970s that showed stuttering in preschool children could be reduced by verbal contingencies. ${ }^{18,31}$ In this respect, principles of operant conditioning form the bases for the Lidcombe Program. ${ }^{32}$ The Lidcombe Program is one of the most documented treatments for stuttering. Numerous outcome and efficacy trials indicate that the program results in decreased stuttering. ${ }^{33-35}$ A randomized controlled trial ${ }^{36}$ reported a significant difference between a Lidcombe Program treatment group (25 children) and a non-treatment control group (25 children) at 9 months after randomization. The average frequency of stuttering was $1.5 \%$ for the treatment group and $3.9 \%$ for the nontreatment group. The study supported the importance of early intervention for stuttering using the Lidcombe Program.

The Lidcombe Program is divided into two phases. Stage one is the main component of treatment and involves daily measurement of stuttering and parent training to apply verbal contingencies to stutter-free and stuttered speech. Stage two is a longer term follow-up stage. In recognition that stuttering is a relapse prone disorder, stage two is designed to prevent relapse. In stage two, the time between clinic visits increases and parents are more reliant on their own skills and knowledge to detect possible relapse.

In the beginning of stage one, parents identify moments of stuttering. Different types of stuttering (ie, repeated movements and fixed postures) and differences in stuttering severity are discussed. Parents are instructed to rate the severity of their child's stuttering daily and bring the graph sheet to each weekly clinic visit. The rating scale is easy to use. The scale is one to ten, where one reflects no stuttering, two reflects very mild stuttering, and ten reflects extremely severe stuttering. The numbers between two and ten are not defined. The score is a global severity rating assigned for the whole day. Therefore, parents are encouraged to score their child's stuttering severity in the evening. The scale has been shown to be easily completed by parents, is not time consuming, and parents can be reliable with minimal training. The child's compliance is also not required, which can be a significant advantage when working with young preschoolaged children. The daily severity score is considered an essential component of the treatment as it guides the need for other intervention.

The primary treatment component involves parents applying verbal contingencies for stutter-free speech and unambiguous stuttering. Verbal contingencies for stutter-free speech may include praise (eg, "good talking!" "nice smooth talking!") and/or acknowledgment of stutter-free speech (eg, "that was smooth"). Acknowledgement is delivered in 
a neutral tone of voice and can be used in conjunction with praise. Acknowledgment may be useful for children who are sensitive to praise and to make sure praise is not overdone. Parents may also request self-evaluation from the child (ie, "did you say that smoothly?" "Did you hear any bumps?"). Requests for self-evaluation are only used for stutter-free speech. The expected answer for self-evaluation requests is always an affirmation that the child's speech was, in fact, free of stuttering moments. The majority of all contingencies should be for stutter-free speech.

Contingencies for unambiguous stuttering may also be given. Only unambiguous stuttering is addressed so as not to instill confusion in the child. Acknowledging stuttering should be used with caution. It should not be used if the contingency appears to be stressful to the child. The ratio of positive to negative contingencies should be minimally $5: 1$. Acknowledgment of stuttering should always be given in a neutral tone, and may take the form of "I heard a bump," "That was a bump," or "That wasn't smooth." Parents may also request self-correction for unambiguous stuttered speech. For example, "Can you say that again?" Again, this strategy should only be used if the child is not reacting negatively.

The use of verbal contingencies for stutter-free and stuttered speech begins in structured conversations. The first conversations containing contingencies should be carefully structured so that the child is likely to be mostly stutter-free. The treatment progresses to parents using contingencies in unstructured daily conversations once the parent is adept at providing the contingencies in structured conversations. Children move to stage two when parents have reported one week of severity ratings of one (no stuttering) or two (very mild stuttering).

\section{Combined approaches}

The two treatments for preschool children outlined above differ in their focus on reducing demands on the child (the multifactorial approach) or in the use of response contingent stimulation (the Lidcombe Program). The multifactorial model focuses on modifying interpersonal stressors and simplifying the communication style between child and caregiver. In contrast, the Lidcombe Program focuses nearly exclusively on the principles of operant conditioning. There is much debate about the superiority of each approach. ${ }^{37}$ However, one similarity, or acknowledgement, is that parents play a vital role in helping their children overcome their stuttering. Both approaches rely on families that are willing and able to participate. ${ }^{19}$ This prerequisite may make it difficult or impossible to use these approaches when family support is lacking or absent.

Currently the Lidcombe Program is the only treatment supported by Phase I to Phase III clinical trials. The multifactorial approaches have some preliminary evidence of success, but more research is clearly needed. What has perhaps been lost in the many discussions about the merits and pitfalls of each approach is that the two approaches may be used synergistically. While no studies have assessed a combined approach, it is likely that many SLPs are already doing this. These approaches are not necessarily dichotomous. The multifactorial model may provide a structured starting point in helping parents understand stuttering. Knowledge about stuttering can maximize a healthy and appropriate communication environment between parent and child. If the child does not respond to mostly indirect environmental and communicative manipulations then a more direct approach would be dictated.

\section{Treatments for adults}

There is also much disagreement regarding the essential components of stuttering treatment for adults. ${ }^{38-42}$ While many different treatment approaches exist to treat stuttering in adults, most of the approaches can be separated into two groups. The groups include those approaches dedicated primarily to (1) cognitive/anxiolytic issues, or (2) dedicated primarily to increasing speech fluency. These groups are referred to as "stuttering management" and "speech restructuring," respectively. ${ }^{43}$

\section{Stuttering management}

Stuttering management therapies started in the 1930s with the work of Lee Travis and Bryng Bryngelson. ${ }^{44}$ This early treatment required attitude change and social adjustment to help the person who stuttered to deal with the social and vocational ramifications of stuttering. One treatment technique that has remained a central feature of stuttering management therapies is that of "voluntary stuttering." This procedure originated from the Negative Practice techniques introduced by Knight Dunlap. ${ }^{45}$ Later, stuttering management therapies evolved with the work of Bloodstein, ${ }^{46}$ Johnson, ${ }^{47}$ Sheehan, ${ }^{21,48}$ Van Riper, ${ }^{49}$ and Williams. ${ }^{50}$ Since most of these therapies originated at The University of Iowa, they are also referred to as the "Iowa Approach." 51

Stuttering management therapy focuses on desensitization to stuttering (eg, through voluntary stuttering) and includes stuttering modification techniques designed to reduce muscular tension associated with stuttering moments. 
Like most desensitization therapies, stuttering management therapy has its origin in the cognitive learning literature. ${ }^{52-54}$ The main goals of stuttering management therapy are to develop acceptance of stuttering, reduce fear and anxiety associated with stuttering, and to teach the person who stutters to stutter with decreased effort. ${ }^{55}$

Over time, most adults and adolescents who stutter develop a set of adverse reactions to their stuttering. To address this problem, stuttering management therapy may also involve basic elements of cognitive behavior therapy (CBT). CBT is used with individuals experiencing debilitating levels of social anxiety related to stuttering and speaking. It has been reported that approximately $50 \%$ of adults who stutter may have significantly high levels of social anxiety. ${ }^{56,57}$ The goal of CBT is to reduce social avoidance and anxiety. ${ }^{58,59}$

The basic premise of CBT is that emotional reactions and behavior are influenced by cognitions. A person's thoughts, opinions, and interpretations about themselves influence their emotional state. A process of cognitive restructuring can promote improved self-control and improved self-concept. Improved control can likewise lead to decreased feelings of self-deprecation and emotions of shame and fear related to stuttering.

The core component of CBT for people who stutter is challenging unhelpful beliefs about possible negative evaluations by others. Specifically, CBT used in stuttering treatment can lead to reduced anxiety and social avoidance. ${ }^{60}$ CBT therapy comprises a series of sessions where negative thoughts related to stuttering and social interaction are systematically modified. The first step is for the client and therapist to develop an understanding of the problem. Patterns of unhelpful thoughts are identified. Clients then re-evaluate their negative thoughts that they have related to their speech and their stuttering. In the context of stuttering, evaluating negative thoughts may be accomplished through multiple means: (1) individual counseling involving "reframing" negative thoughts and emotions, (2) group problemsolving discussions related to anxiety management, and (3) systematic desensitization of stuttering fears by using disclosure and pseudo-stuttering.

A long standing problem with stuttering management approaches is that treatment-effectiveness research is lacking. ${ }^{55}$ Blomgren et $\mathrm{ll}^{38}$ recently evaluated the clinical effectiveness of a three week intensive stuttering management program. The study indicated that the approach did not treat stuttered speech per se, but rather the acceptance, avoidance, stigmatic, and anxiolytic symptoms of the disorder. Two all-encompassing conclusions were proposed. The first was that stuttering frequency does not appear to decrease automatically with reductions in self-reported anxiety. The second was that, even in the absence of decreases in stuttering frequency, it is possible to treat anxiety and avoidance related to stuttering.

\section{Speech restructuring approaches}

Speech restructuring refers to speech therapy where a client is taught to use a new speech pattern. These approaches are also called "fluency shaping" or "prolonged speech" treatments. Slowed or prolonged speech is typically the primary component of any new speech pattern. The person who stutters is also taught to make speech motor movements with less articulatory pressure and to initiate vocal fold vibration in a gradual and controlled manner. The premise is that stuttering speakers habitually use speech production strategies that are outside their speech motor control abilities. The goal of speech restructuring is to promote a new speech production pattern that is conducive to fluent speech.

Some speech restructuring approaches focus exclusively on speech rate reduction. These approaches use prolonged speech as the sole or primary technique ${ }^{61-64}$ The specific prolonged speech techniques are also referred to as "stretched syllables," "controlled rate," "slow speech," or "smooth speech" techniques. Other speech restructuring approaches combine prolonged speech with other fluency enhancing techniques. ${ }^{65-68}$

Speech restructuring therapy is an evidence-based approach to helping people who stutter improve their control over their speaking mechanism. A relatively wide range of published studies indicate that speech restructuring therapy does reduce stuttering frequency. ${ }^{44,69-72}$ However, most "pure" speech restructuring approaches do not address negative feelings, unhelpful attitudes, or anxiety related to stuttering. Furthermore, while speech restructuring therapies can result in quite dramatic decreases in in-clinic stuttering frequency, maintaining constant control in everyday speaking situations can be very difficult. Stuttering is also susceptible to relapse, so teaching stuttering management skills to deal with the stuttering when it occurs is prudent.

\section{Comprehensive approaches}

As indicated above, proponents of stuttering management and speech restructuring approaches have long been at odds. For multiple decades, each theoretical camp held antithetical viewpoints. At times the interaction between the camps was nothing less than hostile. More recently, there has been an attempt to combine stuttering management and speech 
restructuring approaches. In North America, examples include well-known intensive stuttering programs such as the Comprehensive Stuttering Program at the University of Alberta, ${ }^{66,73}$ the Intensive Treatment Program at the American Institute of Stuttering, ${ }^{74}$ and the Fluency Plus Program. ${ }^{67}$ While these programs are primarily based in the speech restructuring approaches, all have recently added stuttering management components.

A comprehensive approach to stuttering treatment includes dealing with both the surface elements of stuttering as well as the deeper attributes of stuttering such as anxiety, fear of stuttering, approach-avoidance issues, self-confidence issues, and self-perception issues. ${ }^{6}$ This multidimensional approach follows the mandate of the World Health Organization (WHO, Geneva, Switzerland). The WHO advocates a multidimensional paradigm of human health conditions, which includes the concepts of "impairment," "activity limitation," and "participation restrictions." The WHO model has been implemented as a model for evaluating both surface stuttering and the adverse consequences of stuttering. ${ }^{75-78}$ In this vein, stuttering treatments should only be considered successful if they reduce stuttering frequency (impairment level) and also reduce "participation restrictions or activity limitations."

Stuttering treatment is usually most effective when implemented in an intensive manner. ${ }^{68}$ The rationale is similar to the immersion principle in second language learning; that is, new skills as complicated as learning a new language (or a new speaking pattern) are best accomplished in an intensive, or immersive, manner.

The University of Utah Intensive Stuttering Clinic (UUISC) is one example of a comprehensive approach to treating stuttering. The UUISC is based on the speech restructuring techniques developed by Webster, ${ }^{68,72}$ Boberg and Kully, ${ }^{66}$ and $\mathrm{Kroll}^{79}$ as well as stuttering management and cognitive-behavioral/desensitization approaches influenced by Van Riper ${ }^{49}$ and Breitenfeldt and Lorenz. ${ }^{80}$ The UUISC is based on the perspective that stuttering is a multidimensional disorder that demands a multidimensional approach to treat. At its core, stuttering is a disorder of speech motor control. However, the disorder is more than the stuttering moments; the broader experience of stuttering involves a lifetime of dealing with anxiety and avoidance caused by the stuttering. Therefore, the UUISC targets both improved speech fluency and stuttering management.

The UUISC is an annual clinic and approximately 80 clients have participated in the treatment since 2003. Normally, six to ten clients participate in each clinic.
The clinic involves approximately 60 hours of treatment. Clients are seen from 9 am to 4 pm on weekdays for 2 weeks. Treatment encompasses a combination of individual and group sessions. A detailed therapy manual is available, ${ }^{65}$ and significant treatment outcomes have been presented. ${ }^{65,81}$

The goals for the clinic are for clients to:

- Learn new speaking skills that facilitate fluent speech

- Reduce the number and severity of stuttering moments

- Foster a proactive attitude toward improving speech production

- Foster a good understanding and healthy acceptance of stuttering

- Manage stress and anxiety related to stuttering and speaking

- Practice learned techniques in real-life situations

- Increase self-confidence related to speaking.

A series of speech restructuring strategies are utilized.

These techniques are based on those used in the Stuttering Treatment Center at the Hollins Communications Research Institute in Roanoke Virginia, ${ }^{68,72}$ and at the Institute of Stuttering Treatment and Research at the University of Alberta ${ }^{66}$ There are three core fluency facilitating techniques utilized in the UUISC: (1) the stretched syllable target, (2) the gentle phonatory onset target, and (3) the reduced articulatory pressure target. There are four supplemental techniques: (1) the full breath target, (2) the smooth articulatory change target, (3) the continuous phonation target, and (4) the full articulatory movement target. These techniques are considered "supplemental" because not every stuttering speaker is asked to use these techniques. For most clients, the three core targets of the UUISC are adequate to promote controlled speech fluency. One or more supplemental techniques may be prescribed if they are considered helpful for facilitating fluent speech for an individual speaker.

The primary goal of the stretched syllable target is to stretch the duration of each and every spoken syllable. This "slow motion" speech allows an individual to notice and alter their speech sound production. The stretched syllable technique results in reduced force and abruptness of articulatory movements. During stuttered speech, syllable durations are often shorter than normal and pauses are longer than normal. ${ }^{68}$ The prolongation of syllables results in increased control over the articulatory movements of speech.

Prolonged speech has been found to be the most efficacious fluency facilitating technique ${ }^{82}$ and is the primary fluency technique in nearly all speech restructuring therapies. Speech rate may be decreased by lengthening the duration of syllables or by pausing longer between utterances. 
An utterance is all the words one speaks on a single breath. Decreasing speech rate is best achieved by stretching the duration of syllables, not necessarily by inserting longer pauses between utterances. Initially, speech is produced at a very slow rate. In the UUISC each syllable is prolonged for two seconds. After fluent speech has been established at 2-second stretch, syllable durations are systematically shortened to 1 second, 0.5 seconds, and finally to "controlled normal rate." Controlled normal rate is the rate that a person who stutters can speak with little or no stuttering. The final rate varies for each client.

The gentle vocal onset technique provides a strategy for stuttering speakers to initiate vocal fold vibration in a controlled, precise, and relaxed manner. The gentle onset technique is used on words that begin with vowels and voiced consonants. This technique can be very helpful since many people who stutter make some speech sounds with hard vocal onsets. They initiate voicing with too much force and muscular rigidity. This high level of tension results in a greater propensity for a stuttering moment to occur. The third and final core technique is reduced articulatory pressure. This technique targets the tongue and lips primarily. The technique provides a way for speakers to reduce articulatory pressure and smoothly transition from speech sound to the next in running speech.

Five stuttering management techniques are applied throughout the clinic. Stuttering management techniques are used to (1) decrease the likelihood of a severe stuttering moment from occurring in the first place, and (2) to lessen the severity of stuttering moments when they do occur. In this respect, some stuttering management techniques are proactive and others are reactive. ${ }^{65}$

The proactive techniques include (1) maintaining eye contact, (2) openly disclosing one stutters, and (3) pseudostuttering. Using appropriate eye contact, disclosing or advertising that one stutters, and pseudo-stuttering are proactive because these techniques allow the individual to minimize the impact of stuttering early in a conversation. Reactive techniques include (1) purposefully terminating a stuttering moment, and (2) cancelling a stuttered word by repeating it fluently. Purposefully terminating a stuttering moment and cancelling a stuttered word are reactive because the speaker uses the techniques to react to a moment of stuttering after it has already begun. Cancelling a stuttered word essentially allows the individual to restabilize their speech once stuttering has begun.

Maintaining appropriate eye contact during a conversation is a good communication skill for everybody and is very important for people who stutter. Maintaining eye contact is especially important during moments of stuttering. Maintaining eye contact lets a conversational partner know that (1) the speaker is in control of the conversation, (2) that the speaker is not embarrassed by any stuttering that may be present, and (3) that the speaker values the communication that is taking place. ${ }^{80,83}$

Finally, disclosure of one's stuttering is also an essential stuttering management technique. ${ }^{84,85}$ Many people who stutter spend much effort attempting to hide the fact that they stutter. People who stutter try to hide their stuttering for numerous reasons. These include fear of embarrassment, fear of social punishment, poor acceptance of their disorder, or perhaps simple habit after years of avoiding problem sounds, words, or speaking contexts. Breitenfeldt and Lorenz ${ }^{80}$ list three approaches to disclosing one's stuttering: (1) the direct route in which one simply states that they stutter - either at the very beginning of a conversation or immediately after the first stuttering moment, (2) by using humor - following a moment of stuttering one can make a joke about it to help put a conversational partner at ease, and (3) the pseudostuttering (fake stuttering) approach in which the speaker stutters on purpose. In order for a pseudo-stutter not to turn into an uncontrolled stutter, it is important the stutter be produced in a slow, controlled, and deliberate manner. Pseudo stuttering has two main benefits: (1) it serves as an obvious way to advertise stuttering early in a conversation and (2) pseudo-stuttering can benefit people who stutter by helping them become desensitized to their stuttering. The idea is based on the notion that what a person can do deliberately should not be feared.

\section{Summary}

The purpose of this article was to provide examples of modern behavioral treatments for stuttering in children and adults. A small number of representative treatment approaches were described. It would have been impossible to review all available treatments for stuttering in a single article so, regrettably, a number of approaches are absent. My apologies to my many esteemed colleagues whose approaches were omitted or mentioned only in passing.

Treatment for children who stutter has historically fluctuated between direct therapies and indirect therapies. Direct therapies focus directly on the child. Indirect therapies focus on the parents of the stuttering child. Current therapies for children are distinguished primarily by the multifactorial treatments and the response contingent therapies. Multifactorial treatments work on altering 
parent-child interactions, mediating interpersonal stressors, and generally providing a supportive communicative environment. Response contingent therapies, such as the Lidcombe Program, focus on providing consequences for stutter free and stuttered speech. Nearly all current approaches to treating stuttering in children involve parental training. Regardless of the treatment approach, however, the high rate of spontaneous recovery in children provides a statistical challenge for determining treatment effectiveness.

For adults, stuttering therapy has traditionally focused on either (1) teaching new ways to manage and deal with the stuttering or (2) teaching new ways of speaking that facilitate fluent speech. These two approaches (stuttering management and speech restructuring, respectively) are increasingly used in concert to help people who stutter to deal with the core stuttering behavior as well as the affective, anxiolytic, emotional, and cognitive aspects of the disorder. In all cases, the stuttering speaker is challenged to cease previously unhelpful behaviors and substitute new productive ones. Ultimately, therapy must be tailored to the individual needs of the clients. There is currently no cure for stuttering in adults, so all therapy techniques are, in essence, compensatory. The nature of compensatory techniques is that they must be used continuously to maintain improvement. Therefore, it is imperative that any stuttering treatment incorporates a longterm strategy of teaching clients to be their own clinicians and also offering opportunities for long-term therapeutic follow-up.

While this article focused on treatments for younger children and adults, treatment for school-age children ought not to be completely overlooked. It should not be a surprise that treatments for this age group often include combinations of the techniques discussed for younger children and those for adults. The main modification in transitioning from a preschool child to a school-aged child is the new emphasis on speech production strategies, such as prolonged speech. As a child gains metalinguistic awareness, it becomes increasingly easier to teach fluency facilitating techniques that require conscious control over speech motor mechanisms. Also, as a child matures, the need to address the anxiolytic, acceptance, and self-esteem issues generally becomes more pronounced. While the ultimate goal for preschool children is to stop stuttering, the goal for school-aged children and adults is not, or should not, be complete fluency. Successful treatment outcomes may be defined by modest decreases in stuttering frequency, shorter stuttering moments, decreased struggle to speak, decreased avoidance behavior, decreased anxiety associated with speaking, and improved social, educational, and occupational engagement.
While the emphasis of this article was on behavioral techniques, nonbehavioral treatment approaches also exist. For instance, pharmacological treatments are emerging, ${ }^{86}$ delayed auditory feedback (ie, the SpeechEasy device [Janus Development Group, Inc, Greenville, NC, USA]) has a long history in stuttering therapy, ${ }^{87}$ and even the effects of acupuncture have been examined (albeit with entirely negative results) ${ }^{88}$ While none of these approaches has proven to provide long term amelioration of stuttering, future behavioral treatments may well include pharmacological adjuvants and may increasingly incorporate a variety of emerging technologies such as portable biofeedback devices and web-facilitated treatment options.

\section{Disclosure}

The author reports no conflicts of interest in this work.

\section{References}

1. Bloodstein O, Ratner NB. A Handbook on Stuttering, 6th ed. Clifton Park, NY: Thomson Delmar Learning; 2008.

2. Yairi E, Ambrose NG, Paden EP, Throneburg RN. Predictive factors of persistence and recovery: pathways of childhood stuttering. J Commun Disord. 1996;29(1):51-77.

3. Teesson K, Packman A, Onslow M. The Lidcombe Behavioral Data Language of stuttering. J Speech Lang Hear Res. 2003;46(4): 1009-1015.

4. Bennett EM. Working with People Who Stutter: A Lifespan Approach Upper Saddle River, NJ: Pearson/Merrill/Prentice Hall; 2006.

5. Smith A, Kelly E. Stuttering: a dynamic, multifactorial model. In: Curlee RF, Siegel GM, editors. Nature and Treatment of Stuttering: New Directions, 2nd ed. Boston: Allyn and Bacon; 1997:204-217.

6. Blomgren M. Stuttering treatment outcomes measurement: Asssessing above and below the surface. Perspect Fluen Fluen Disord. 2007; 17(3):19-23

7. Blumgart E, Tran Y, Craig A. Social anxiety disorder in adults who stutter. Depress Anxiety. 2010;27(7):687-692.

8. Gabel RM, Hughes S, Daniels D. Effects of stuttering severity and therapy involvement on role entrapment of people who stutter J Commun Disord. 2008;41(2):146-158.

9. Packman A, Attanasio JS. Theoretical Issues in Stuttering. Hove, East Sussex; New York: Psychology Press; 2004

10. Blomgren M, Nagarajan SS, Lee JN, Li T, Alvord L. Preliminary results of a functional MRI study of brain activation patterns in stuttering and nonstuttering speakers during a lexical access task. J Fluency Disord. 2003;28(4):337-355; quiz 355-336

11. Ingham RJ. Neuroimaging in Communication Sciences and Disorders. San Diego, CA: Plural Pub; 2008.

12. Salmelin R, Schnitzler A, Schmitz F, Freund HJ. Single word reading in developmental stutterers and fluent speakers. Brain. 2000;123(Pt 6): 1184-1202.

13. Bennett E. Working with People Who Stutter: A Lifespan Approach. Upper Saddle River, NJ: Pearson/Merrill/Prentice Hall; 2006.

14. Yairi E, Seery CH. Stuttering: Foundations and Clinical Applications. Boston: Pearson; 2011.

15. Jelčić Jakšić S, Onslow M. The Science and Practice of Stuttering Treatment: A Symposium. West Sussex, UK: Wiley-Blackwell; 2012.

16. Bothe AK. Evidence-Based Treatment of Stuttering: Empirical Bases and Clinical Applications. Mahwah, NJ: L. Erlbaum; 2004.

17. Guitar B, McCauley RJ. Treatment of Stuttering: Established And Emerging Approaches, 1st ed. Baltimore, MD: Lippincott Williams \& Wilkins; 2010 
18. Martin RR, Kuhl P, Haroldson S. An experimental treatment with two preschool stuttering children. J Speech Hear Res. 1972;15(4): $743-752$.

19. Lasan M. Multifactorial treatment for preschool children. In: Jelcic Jaksic S, Onslow M, editors. The Science and Practice of Stuttering Treatment: A Symposium. West Sussex, UK: Wiley-Blackwell; 2012:171-181.

20. Andrews G, Craig A, Feyer AM, Hoddinott S, Howie P, Neilson M. Stuttering: a review of research findings and theories circa 1982. J Speech Hear Disord. 1983;48(3):226-246.

21. Sheehan JG. Stuttering; Research and Therapy. New York: Harper and Row; 1970.

22. Starkweather CW. Fluency and Stuttering. Englewood Cliffs, NJ: Prentice-Hall; 1987.

23. Yaruss JS, Coleman C, Hammer D. Treating preschool children who stutter: description and preliminary evaluation of a family-focused treatment approach. Lang Speech Hear Serv Sch. 2006;37(2): $118-136$.

24. Millard SK, Nicholas A, Cook FM. Is parent-child interaction therapy effective in reducing stuttering? J Speech Lang Hear Res. 2008; 51(3):636-650.

25. Millard SK, Edwards S, Cook FM. Parent-child interaction therapy: Adding to the evidence. Int J Speech Lang Pa. 2009;11(1):61-76.

26. Rustin L, Botterill W, Kelman E. Assessment and Therapy for Young Dysfluent Children: Family Interaction. San Diego: Singular Pub. Group; 1996.

27. Conture EG. Stuttering: Its Nature, Diagnosis, and Treatment. Boston, MA: Allyn and Bacon; 2001.

28. Conture E, Melnick K. Parent-child group approach to stuttering in preschool and school-age children. In: Onslow M, Packman A, editors. Early Stuttering: A Handbook of Intervention Strategies. San Diego: Singular; 1999:17-51.

29. Richels C, Conture E. An indirect treatment approach for early intervention for childhood stuttering. In: Conture E, Curlee R, editors. Stuttering and Related Disorder, 3rd ed. New York: Thieme; 2007.

30. Franken MC, Kielstra-Van der Schalk CJ, Boelens H. Experimental treatment of early stuttering: a preliminary study. J Fluency Disord. 2005;30(3):189-199.

31. Reed C, Godden A. An experimental treatment using verbal punishment with two preschool stutterers. J Fluency Disord. 1977;2: 225-233.

32. Harrison E, Onslow M. The Lidcombe Program for preschool children who stutter. In: Guitar B, McCauley R, editors. Treatment of Stuttering: Established and Emerging Interventions. Baltimore, MD: Lippincott Williams \& Wilkins; 2009:118-140.

33. Onslow M, Costa L, Rue S. Direct early intervention with stuttering: some preliminary data. J Speech Hear Disord. 1990;55(3): 405-416.

34. Onslow M, Andrews C, Lincoln M. A control/experimental trial of an operant treatment for early stuttering. J Speech Hear Res. 1994;37(6): 1244-1259.

35. Jones M, Onslow M, Harrison E, Packman A. Treating stuttering in young children: Predicting treatment time in the lidcombe program. J Speech Lang Hear R. 2000;43(6):1440-1450.

36. Jones M, Onslow M, Packman A, et al. Randomised controlled trial of the Lidcombe programme of early stuttering intervention. BMJ. 2005; 331(7518):659-661.

37. Onslow M, Yaruss JS. Differing perspectives on what to do with a stuttering preschooler and why. Am J Speech Lang Pathol. 2007; 16(1):65-68.

38. Blomgren M, Roy N, Callister T, Merrill RM. Intensive stuttering modification therapy: a multidimensional assessment of treatment outcomes. J Speech Lang Hear Res. 2005;48(3):509-523.

39. Blomgren M, Roy N, Callister T, Merrill R. Treatment outcomes research: A response to Ryan. J Speech Lang Hear Res. 2006;49: 1415-1419.
40. Blomgren M, Roy N, Callister T, Merrill R. Assessing stuttering treatment without assissing stuttering? A response to Reitzes and Snyder. J Speech Lang Hear Res. 2006;49:1423-1426.

41. Reitzes P, Snyder G. Response to "Intensive stuttering modification therapy: a multidimensional assessment of treatment outcomes," by Blomgren, Roy, Callister, and Merrill (2005). J Speech Lang Hear Res. 2006;49(6):1420-1422; author reply 1423-1426.

42. Ryan BP. Response to Blomgren, Roy, Callister, and Merrill (2005). J Speech Lang Hear Res. 2006;49(6):1412-1414; author reply 1415-1419.

43. Blomgren M. Stuttering treatment for adults: an update on contemporary approaches. Semin Speech Lang. 2010;31(4):272-282.

44. Ingham RJ. Stuttering and Behavior Therapy: Current Status and Experimental Foundations. San Diego: College-Hill Press; 1984.

45. Dunlap K. Habits: Their Making and Unmaking. New York: Liveright; 1932.

46. Bloodstein O. Stuttering as tension and fragmentation. In: Eisenson J, editor. Stuttering: A Symposium. New York: Harper; 1975:1-96.

47. Johnson W. Stuttering. In: Moeller WJD, editor. Speech-Handicapped School Children. New York: Harper and Row; 1967:229-329.

48. Sheehan J. Current issues on stuttering and recovery. In: Gregory $\mathrm{HH}$, editor. Controversies About Stuttering Therapy. Baltimore, MD: University Park Press; 1979:175-208.

49. Van Riper C. The Treatment of Stuttering. Englewood Cliffs, NJ: Prentice-Hall; 1973

50. Williams DE. Stuttering therapy for children. In: Travis LE, editor. Handbook of Speech Pathology and Audiology. Englewood Cliffs, NJ: Prentice-Hall; 1971:1073-1093.

51. Zebrowski PM, Arenas RM. The "Iowa Way" revisited. J Fluency Disord. 2011;36(3):144-157.

52. Bandura A. Self-efficacy: toward a unifying theory of behavioral change. Psychol Rev. 1977;84(2):191-215.

53. Bandura A. Social Foundations of Thought and Action. Englewood Cliffs, NJ: Prentice-Hall; 1986.

54. Wolpe J. Psychotherapy by Reciprocal Inhibition. Stanford, CA: Stanford University Press; 1958.

55. Blomgren M. Review of the Successful Stuttering Management Program. In: Jelčić Jakšić S, Onslow M, editors. The Science and Practice of Stuttering Treatment: A Symposium. Chichester, UK: John Wiley \& Sons, Ltd; 2012:99-113.

56. Kraaimaat FW, Vanryckeghem M, Van Dam-Baggen R. Stuttering and social anxiety. J Fluency Disord. 2002;27(4):319-330; quiz 330-311.

57. Menzies RG, O’Brian S, Onslow M, Packman A, St Clare T, Block S. An experimental clinical trial of a cognitive-behavior therapy package for chronic stuttering. J Speech Lang Hear Res. 2008;51(6):1451-1464.

58. Craig AR, Tran Y. Fear of speaking: Chronic anxiety and stuttering. Advances in Psychiatric Treatment. 2006;12:63-68.

59. Menzies RG, Onslow M, Packman A, O’Brian S. Cognitive behavior therapy for adults who stutter: a tutorial for speech-language pathologists. J Fluency Disord. 2009;34(3):187-200.

60. Rowley D. Cognitive behaviour therapy. In: Jelčić Jakšić S, Onslow M, editors. The Science and Practice of Stuttering Treatment: A Symposium. Chichester, UK: John Wiley \& Sons, Ltd; 2012:183-193.

61. Howie PM, Tanner S, Andrews G. Short- and long-term outcome in an intensive treatment program for adult stutterers. J Speech Hear Disord. 1981;46(1):104-109.

62. Ingham RJ. Operant methodology in stuttering therapy. In: Eisenson J, editor. Stuttering: A Scond Symposium. New York: Harper and Row; 1975.

63. O'Brian S, Packman A, Onslow M. The Camperdown Program. In: Guitar B, McCauley R, editors. Treatment of Stuttering: Established and Emerging Interventions. Philadelphia: Wolters Kluwer/Lippencott Williams \& Wilkins; 2010:256-276. 
64. Ryan BP. Programmed Therapy for Stuttering in Children and Adults. Springfield, IL: Thomas; 1974.

65. Blomgren M. University of Utah Instensive Stuttering Clinic Therapy Manual. Acton, MA: Copley Custon Textbooks; 2009.

66. Boberg E, Kully D. Comprehensive Stuttering Program: Clinical Manual. San Diego: College-Hill Press; 1985.

67. Kroll R, Scott-Sulsky L. The Fluency Plus Program: An integration of fluency shaping and cognitive restructuring procedures for adolescents and adults who stutter. In: Guitar B, McCauley R, editors. Treatment of Stuttering: Established and Emerging Interventions. Philadelphia: Wolters Kluwer/Lippincott Williams \& Wilkins; 2010:277-311.

68. Webster RL. Precision Fluency Shaping Program: Speech Reconstruction for Stutterers. Roanoke, VA: Communications Development Corporation; 1982.

69. O'Brian S, Onslow M, Cream A, Packman A. The Camperdown Program: outcomes of a new prolonged-speech treatment model. J Speech Lang Hear Res. 2003;46(4):933-946.

70. O'Brian S, Packman A, Onslow M. Telehealth delivery of the Camperdown Program for adults who stutter: a phase I trial. J Speech Lang Hear Res. 2008;51(1):184-195.

71. Goldiamond I. Stuttering and fluency as manipulatable operant response classes. In: Krasner L, Ullmann LP, editors. Research in Behavior Modification. New York: Holt, Rinehart and Winston; 1965.

72. Webster RL. Evolution of a target-based behavioral therapy for stuttering. In: Shames GH, Rubin H, editors. Stuttering Then and Now. Columbus, OH: Merrill Publishing; 1986:397-414.

73. Kully D, Langevin M, Lomheim H. Intensive treatment of stuttering in adolescents and adults. In: Conture EG, Curlee RF, editors. Stuttering and Related Disorders of Fluency, 3rd ed. New York: Thieme; 2007:213-232.

74. Montgomery CS. The treatment of stuttering: From the hub to the spoke. In: Bernstein Ratner N, Tetnowski JA, editors. Current Issues in Stuttering Research and Practice. Mahway, NJ: Lawrence Erlbaum; 2006:159-204.

75. No authors listed. Guidelines for practice in stuttering treatment. Special Interest Division on Fluency and Fluency Disorders American SpeechLanguage-Hearing Association. ASHA Suppl. 1995;37(3 Suppl 14): 26-35.

76. Finn P, Howard R, Kubala R. Unassisted recovery from stuttering: self-perceptions of current speech behavior, attitudes, and feelings. J Fluency Disord. 2005;30(4):281-305.
77. Yaruss JS. Evaluating treatment outcomes for adults who stutter. J Commun Disord. 2001;34(1-2):163-182.

78. Yaruss JS, Quesal RW. Stuttering and the International Classification of Functioning, Disability, and Health: an update. J Commun Disord. 2004;37(1):35-52.

79. Kroll R. Manual of Fluency Maintenance: Guide for Ongoing Practice. 2nd edition. Toronto: Clarke Institute; 1991.

80. Breitenfeldt DH, Lorenz DR. Successful Stuttering Management Program (SSMP): For Adolescent and Adult Stutterers, 2nd ed. Cheney, WA: Eastern Washington University Press; 1999.

81. Blomgren M, Whitchurch M, Metzger E. The University of Utah Intensive Stuttering Clinic: Treatment Outcomes. Presented at: 6th World Congress on Fluency Disorders; August 5-8; 2009; Rio de Janeiro, Brazil.

82. Andrews G, Guitar B, Howie P. Meta-analysis of the effects of stuttering treatment. J Speech Hear Disord. 1980;45(3):287-307.

83. Webster WG, Poulos M. Facilitating Fluency: Transfer Strategies for Adult Stuttering Treatment Programs. Tucson, AZ: Communication Skill Builders; 1989.

84. Lee K, Manning W. Listener responses according to stuttering selfacknowledgement and modification. J Fluency Disord. 2010;35: $110-122$.

85. Healey EC, Gabel RM, Daniels DE, Kawai N. The effects of selfdisclosure and non self-disclosure of stuttering on listeners' perceptions of a person who stutters. J Fluency Disord. 2007;32(1):51-69.

86. Maguire G, Franklin D, Vatakis NG, et al. Exploratory randomized clinical study of pagoclone in persistent developmental stuttering: the EXamining Pagoclone for peRsistent dEvelopmental Stuttering Study. J Clin Psychopharmacol. 2010;30(1):48-56.

87. Ramig PR, Ellis JB, Pollard R. Application of the SpeechEasy to stuttering treatment: Introduction, background, and preliminary observations. In: Guitar B, McCauley R, editors. Treatment of Stuttering: Established and Emerging Interventions. Baltimore, MD: Lippincott Williams \& Wilkins; 2010:312-328.

88. Craig AR, Kearns M. Results of a traditional acupuncture intervention for stuttering. J Speech Hear Res. 1995;38(3):572-578.

\section{Publish your work in this journal}

Psychology Research and Behavior Management is an international, peerreviewed, open access journal focusing on the science of psychology and its application in behavior management to develop improved outcomes in the clinical, educational, sports and business arenas. Specific topics covered include: Neuroscience, memory \& decision making; Behavior

\section{Dovepress}

modification \& management; Clinical applications; Business \& sports performance management; Social and developmental studies; Animal studies. The manuscript management system is completely online and includes a quick and fair peer-review system. Visit http://www.dovepress. com/testimonials.php to read real quotes from published authors. 